in vain so far as the author and his readers are concerned. The illustrations are taken from well-known workers, but at least the approximate magnifications should be given. Other points, owing to their importance, would require to be traversed in detail, but enough has been said to help those interested to judge whether the book would suit their purpose or not.

\section{A. McWilliam.}

\section{OUR BOOK SHELF.}

Latins et Anglo-Saxons, Races supérieures et Races inférieures. By Prof. N. Colajanni. Translation by Julien Dubois. Pp. $\mathrm{xx}+43^{2}$. (Paris: F. Alcan, I905.) Price 9 francs.

Signor Colajanni, a Socialist deputy and professor of statistics, is a convinced opponent of the doctrine of Anglo-Saxon superiority. The questions which he proposes to himself are, in brief :-(a) the meaning of the terms race and nation; $(b)$ the existence of distinctive racial qualities; $(c)$ the transmission of acquired qualities; $(d)$ the equivalence of decadence in the nation and senescence in the individual. $\mathrm{He}$ concludes $(a)$ that we have no data by which to determine the specific racial attributes of Sergi's European types; $(b)$ that the terms superior and inferior, save as an expression of their relative positions at a given moment, have no meaning when applied to nations; (c) that acquired qualities are transmitted, especially when segregation favours fixation of the type; and (d) that decadence is relative, by comparison with the progress of other nations; nations may, phœnix-like, rise from their ashes and attain a second time to greatness.

Although Signor Colajanni's main arguments are derived from the English and Romance-speaking peoples of the present day, he does not hesitate to invoke the facts of ancient history and the nonEuropean races, and his task is, in fact, one which demands the amplest equipment of historical, sociological, and economic knowledge, combined with an impeccable method and an unerring judgment. Let us illustrate his fitness for his task. A large part of the first half of this work is taken up with the proof of the first and second conclusions cited above; but his method consists largely in putting side by side two or more quotations, primâ facie contradictory, and drawing from them the conclusion that both or all are erroneous. He overlooks the fact that criteria are apt to differ; one author may assert the superiority of a race, another its inferiority; unless the standard is the same, the views are not even shown to be contradictory. Even were it otherwise, it is evident that of two contradictory assertions both are not necessarily wrong.

The statistical methods of the work are not above criticism; on p. 354 we have $\mathrm{I} I 0 / 3=22$; on the following page there is a comparison of the material progress of France and England since I840; for France the savings banks are included; the deposits show an increase of 2200 per cent. Signor Colajanni has no hesitation in taking this as an index number, but he does not add to the English table any corresponding figure for our savings banks; even, therefore, were it legitimate to take the mean of ten index numbers, regardless of their relative importance, as a fair statement of the changes. his method is ludicrously fallacious.

Signor Colajanni's knowledge of England is probably limited; we learn (p. 279) that our distinguishing traits are rudeness, lack of sociability, and pitilessness, and that these are due to fagging at school.
Our lack of generosity and sweetness (douceur) are due (p. 124) to our games and violent exercise--football, of course, and perhaps lawn tennis, or, at an earlier age, battledore and shuttlecock. Of Signor Colajanni's logic we may judge when we read (p. I74 et seq.) of Anglo-Saxon decadence as visible in U.S.A., and later (p. 302) that only one-fourth of its citizens are Anglo-Saxons.

Signor Colajanni's book, though inaccurate, is not without its good points, but it leaves little permanent impression. The translator has little knowledge of English and German to judge by the strange words that often meet the eye.

N. W. T.

Machine Construction and Drawing. By Frank Castle, M.I.M.E. Pp. viii +275. (London : Macmillan and Co., Ltd.) Price $4 s .6 d$.

IN the study of machine construction and drawing the assistance to be derived from books can never be more than of secondary importance. The acquirement of a thorough knowledge of the subject depends principally upon the opportunities which a student may have of coming into daily contact in the workshop with varied examples of good engineering practice, and the use which he makes of these opportunities. Assuming that a youth is fortunately circumstanced, he will be busy at suitable moments compiling a book of miscellaneous notes, containing, amongst other things, many fully-dimensioned sketches taken from machine details lying around him. Along with this work, and very appropriately in the drawing class, he will make working drawings to scale of some of the things sketched in his notebook, and additional examples for sketching and drawing will be provided in the class.

The student will also consult text-books for further information, and the book under review will be found very suitable indeed for the purpose. The author first describes the necessary drawing instruments, and explains their use. He then sets out in detail, with proportional dimensions, various forms of common fastenings, such as rivets, bolts, keys, \&c. Then come chapters containing examples of mill work, followed by others dealing with steam-engine details. The final chapter gives a short account of the physical properties of materials used in construction. Sets of useful exercises occur at intervals, and a few calculations of strengths are given; but the latter are wisely kept in strict subordination.

The drawings which abound throughout the work represent good practice, are fully dimensioned, very clearly printed, and will be appreciated by teachers and students alike.

While not free from minor defects, the book can be cordially recommended for use in drawing classes, and to young engineers who are seeking after knowledge on which to base subsequent work in machine design.

Graphs for Beginners. By W. Jamieson, A.M.I.E.E. Pp. 64. (London: Blackie and Son, 1905.) Price Is. $6 d$.

In order to teach and illustrate the subject, the author in this small volume makes use of a number of interesting graphs relating mainly to technical and commercial subjects, many of them discontinuous, algebraical curves being given only a secondary prace, though the logarithmic or compound interest law is dealt with. The significance of the slope at any point of a graph is enforced by simple and effective examples. The treatment is suggestive and interesting, and the author is justified in hoping that the book will tend to cultivate the observation and stimulate the reasoning powers of the young readers. 